\title{
Metabolomics as a marketing tool for geographical indication products: a literature review
}

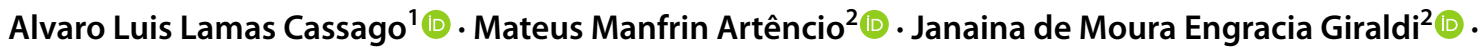 \\ Fernando Batista Da Costa ${ }^{1}$ (i)
}

Received: 16 March 2021 / Revised: 20 May 2021 / Accepted: 22 May 2021 / Published online: 15 June 2021

(c) The Author(s), under exclusive licence to Springer-Verlag GmbH Germany, part of Springer Nature 2021

\begin{abstract}
Geographical indication (GI) is used to identify a product's origin when its characteristics or quality are a result of geographical origin, which includes agricultural products and foodstuff. Metabolomics is an "omics" technique that can support product authentication by providing a chemical fingerprint of a biological system, such as plant and plant-derived products. The main purpose of this article is to verify possible contributions of metabolomic studies to the marketing field, mainly for certified regions, through an integrative review of the literature and maps produced by VOSviewer software. The results indicate that studies based on metabolomics approaches can relate specific food attributes to the region's terroir and knowhow. The evidence of this connection, marketing of GIs and metabolomics methods, is viewed as potential tool for marketing purposes (e.g., to assist communication of positive aspects and quality), and legal protection. In addition, our results provide a taxonomic categorization that can guide future marketing research involving metabolomics. Moreover, the results are also useful to government agencies to improve GIs registration systems and promotion strategies.
\end{abstract}

Keywords Geographical indication $\cdot$ Metabolomics $\cdot$ Certification of origin $\cdot$ Integrative literature review $\cdot$ VOSviewer

\section{Introduction}

Consumer attitudes, habits, and behaviors toward food have changed over the years, especially regarding its characteristics, production systems, and consumption patterns [58]. To meet consumers' demands for safety, quality, and distinguish the offer from competitors', producers differentiate

Alvaro Luis Lamas Cassago

alvaro.cassago@usp.br

Mateus Manfrin Artêncio

mateus.manfrin@usp.br

Janaina de Moura Engracia Giraldi

jgiraldi@usp.br

Fernando Batista Da Costa

febcosta@fcfrp.usp.br

1 Department of Pharmaceutical Sciences, University of São Paulo (USP), School of Pharmaceutical Sciences of Ribeirão Preto, Av. do Café s/n, Ribeirão Preto, SP 14040-903, Brazil

2 Department of Business Administration, University of São Paulo, School of Economics, Business Administration and Accounting of Ribeirão Preto, Av. Bandeirantes, 3900, Ribeirão Preto, SP 14040-905, Brazil their products through production, distribution, quality standards, and value incorporation, information that should be signaled to consumers [31]. As a result, product certifications of many types have emerged to inform consumers about the product's unique characteristics and to protect producers against fraud and free-riding [82]. For example, such certifications can be given to food, foodstuff, and beverages.

In this context, the origin of the product has emerged as a guarantee of food safety, quality, and differentiation, once the place connotations and emotional values transfer to the product [32]. Albeit certifications of origin vary across countries, one frequent link to the names of products is the geographical indication (GI), used when the product characteristics are strongly related to origin and know-how [20]. Considered a variety of intellectual property, GIs can comprise different levels of certification, such as the protected designation of origin (PDO) and protected geographical indication (PGI), depending on the product category, the portion of raw materials that come from the defined area or the number and which of the production processes take place there [31].

Regarding the economic aspects of GIs, products with GI certification presented a sales value of $€ 74.76$ billion in 
the European Union in 2017 [37, 38]. Since European GI products represent $15.5 \%$ of the total EU agri-food exports, with the U.S.A., China, and Singapore accounting for half of its export value, the EU has special funds for GIs development and support [37, 38]. In 2020, the European Fund for promoting GI products within and outside the EU was around $€ 200$ million [36]. The EU studies and reports also acknowledge that the sales value of products with GI is usually double that for similar products without certification of origin $[37,38]$.

Over time, consistency in marketing strategies and investments in branding can support a strong and positive place reputation and identity, which translates into higher prices and sales [32]. Along with EU reports, studies also confirmed the positive effects of origin labels on sales and price $[1,26]$. Some studies validate the influence that places have on consumers' attitudes, intention to purchase [62] and preferences [86]. The economic benefits of GIs led to the registration of GIs in sectors other than the traditional ones (i.e., fruits and vegetables, fresh meats, pasta and bread, seafood products, etc.) $[37,38]$.

GI registration is a very demanding and bureaucratic process, requiring time, collective investments and efforts [78]. Once acquired, GI certification enables price premia and the access to new marketing channels, advantages that other producers may want to benefit from [82]. GIs can be considered an instrument for the valuation of goods that are territorially distinguished and recognized for their quality, depending on the region from where these goods come from [20].

In this regard, we suggest that metabolomics can be used as a chemical fingerprint system that could be applied to GIs, which could improve the registration processes and protection against frauds. Metabolomics is also a potential tool to improve marketing decisions, such as those related to communication, since chemical fingerprints could be communicated to specific targeted market segments.

Lately, it is observed considerable growth in studies focused on food that verify the metabolic peculiarities of products from GIs, using a set of analytical techniques known as metabolomics to fight against counterfeit products $[8,64,80,92]$.

Metabolomics is considered part of a multidisciplinary approach from the "omics" sciences (i.e., genomics, transcriptomics, and proteomics) that aims to evaluate the correlation between genotype and phenotype profiles of a biological system, which are influenced by genetic and environmental changes [17, 42]. The metabolomics approach is used in large-scale studies of metabolites and, when applied to plants, it involves high-throughput analyses of complex metabolite mixtures. For example, plant metabolomic studies can focus on the investigation of abiotic effects on plants metabolism, to find bioactive compounds in plant matrices [25], in the biogeography of species [75], employed as an authentication tool or quality control for food products [35, 87].

The plant metabolome comprises primary and secondary metabolites, all small molecules. Primary metabolites (amino acids, peptides, carbohydrates, fatty acids, etc.) are important for plant growth and development. Secondary metabolites (flavonoids, alkaloids, tannins, terpenes, etc.) are related to the attraction of pollinators, protection against parasites, pathogens, and herbivores, and are also involved in the perception of color, aroma, and plant flavor [48]. For instance, secondary metabolites are involved in the taste, aroma, color, and quality of wines, which are affected by the terpenes and phenolics found in grape berries [67]. Some metabolomic studies have products with certification of origin as the object of study, aiming to verify and compare the metabolic differences between certified and non-certified samples [81, 85, 103].

Analytical, spectrometric, and computational techniques used in metabolomic studies enable the identification of particular characteristics and nuances of metabolites of plants belonging to the same species, revealing the consequences of region-specific natural resources and human processes involved in the cultivation system. A great variety of agricultural products and foodstuff have already been investigated using metabolomics, such as olive oils [46], wines [64], coffee [5], cheeses [91], hops [72], nuts [13], and vinegars [104]. Furthermore, globalization and smaller economic borders increase the importance of traceability for products with certification of origin as a way to fight fraud and adulteration of certain products [88].

Bearing in mind the certifying character of GIs and the use of plant metabolomics to reveal differences in plant chemical profiles, the purpose of this work is to indicate contributions and opportunities that plant metabolomic studies can bring to marketing issues, especially related to GI regions and products, through an integrative literature review. Despite the vast number of chemical studies on GI products, it is necessary to integrate these concepts with marketing and then move towards promotion and protection matters. There have been no similar studies found across some of the key academic databases (Scopus, Web of Science, Springer) that link metabolomic concepts to the marketing field. The present work is the first study to outline this theoretical scenario, and the results are a basis for structuring a research agenda and taxonomy for the combination of marketing and metabolomic topics.

Despite the vast body of published research, a systematic review to integrate marketing and metabolomics is still missing. Summarizing the literature of both areas involved would provide a research agenda and a taxonomy that could benefit the comprehension of the subjects associated with them [95]. Nevertheless, this work is the first to propose an investigation of the relationship between these two topics, 
both related to the origin of products. The origin is an important extrinsic attribute and sign of quality for the marketing purposes and also the main source of metabolomic variations in agri-food products. Hence, besides de protective character of GIs, there is an opportunity for producers in using metabolomics as proof of product's distinctiveness, therefore evidencing its attributes to consumers through chemical confirmation, or chemical fingerprints.

A brief literature review is presented next to elucidate the concepts examined and analyzed in the integrative literature review.

\section{Literature review}

\section{Origin protection and certification}

Agricultural and food products comprise a highly competitive sector and, although taste and preference play a major role in decision-making processes, products are still very similar and commonly held as commodities by consumers [58]. Often referred to as a "commodity trap", food producers face the challenge of being a direct competitor to every other that offers the same good [2]. In this scenario, price is a powerful tool and sometimes the only attribute capable of influencing consumers' judgment and choices [94].

Since ancient times, the origin of goods has a significant influence on peoples' ideas, once place image and reputation can be directly associated with a product category [32]. Besides, natural conditions (terroir) and local know-how (savoir-faire) proved to be important sources of product distinctiveness that, once properly valued and communicated, could draw consumers' attention and preference [24, 40]. Thus, it was around the origin that producers have cooperatively organized themselves to achieve product differentiation, higher prices, and traceability of local and typical food products through legal protection systems that are assigned to a specific form of production, as well as social traditions, symbols, and regional culture [49].

In an international context, the Agreement on TradeRelated Aspects of Intellectual Property Rights (TRIPSAgreement) was designed in 1994 to regulate the protection of GIs. The GI system can comprise different categories of protection, such as the European Union's PDO and PGI, differing themselves by the number of production processes that take place in the specific region [47].

Changes in social values and consumption patterns driven by media, digitalization, and connectiveness have transformed the way food is produced and assessed by consumers. In a world where globalization intertwines food markets and food is easily available with countless options, legal designs are necessary to ensure the product's origin [40]. Acting also as a quality cue, certifications of origin contributed to economic growth. According to the report on the economic value of EU GIs, there was an increase of $37 \%$ of sales of GI products between 2010 and 2017, representing an amount of EUR 20.2 billion, which was led by French and Italian wines and Italian agricultural products and foodstuffs $[37,38]$. In view of the notable capacity of GI products in levering economic growth, an increase in GI registrations is observed in developing countries and in food categories that were not related to origin before (i.e., Cambodia's Kampot pepper with EU PGI) [65].

Albeit the TRIPS-Agreement provides strong protection and bans the use of the term GI for goods not originating in the registered place, delocalizing terms (i.e., "kind," "gender", "style", "type") are used to confuse consumers and take advantage on the benefits that the communication of the GI bring [101]. Once metabolomic tools can be used to identify specific compounds of agricultural products, they could be applied to support the uniqueness and sustainability of a GI, minimizing the risk of losing its strength as a quality and safety extrinsic cue.

\section{Plant and food metabolomics}

Similar to genomics, proteomics, and transcriptomics (used often in studies involving high-throughput genes, proteins, and transcriptions), the term "metabolomics" was coined in the late $90 \mathrm{~s}$ by Oliver, Winson et al. [73], based on a study using functional yeast genomics as a way to describe approaches to measure all metabolites present in a cell, tissue, or organism during a genetic modification or physiological stimulus [15]. Therefore, metabolomics refers to the study of a biological metabolome system, representing a quantitative description of all endogenous low-weight molecular compounds present in a biological sample (i.e., urine, plasma, plants' leaves, or food) $[17,52,71]$.

However, due to the wide diversity of chemical classes and the solubility of small molecules, especially in the plant kingdom, it is not possible to provide the complete metabolome of an organism employing only one analytical method or analysis protocol. For this reason, for a better view of the metabolomes present in biological samples, it is common to combine separation with detection techniques. Nowadays, the most used separation techniques are gas chromatography (GC), liquid chromatography (LC), and capillary electrophoresis. The most used techniques for compound detection/identification are nuclear magnetic resonance and mass spectrometry (MS) [84] and, when coupled to a separation technique, the colloquial term "hyphenated" is frequently used. In general, GC or LC with tandem mass spectrometry (GC-MS and LC-MS) are the most used approaches for metabolomics platforms due to their high sensitivity or reproducibility in detecting metabolites [12]. 
Metabolomic studies are based on three distinct experimental steps: metabolite extraction, analytical tools for data acquisition, and statistical data analysis $[19,56]$. To obtain a representative sample for future analysis, it is necessary to carry out the extraction using optimized conditions, taking into account aspects such as the solvent characteristics, solvent and sample ratio, and the time frame for extraction $[19,56]$. In summary, Fig. 1 illustrates a metabolomic assay workflow.

Fiehn et al. [41] applied these tools for the first time to determine the chemical profile of transgenic plants, with GC-MS techniques applied to leaf extracts of Arabidopsis thaliana (ecotype and mutant). Besides quantifying more than 300 different compounds, the results showed metabolic divergences among the individuals/samples analyzed [41]. The purpose of metabolomic studies with plants, which was earlier postulated by Sumner, Mendes and Dixon [92], has been widened and diversified from crops' genetic/transgenic improvement to (1) drugs development [23, 29], (2 samples/ compound characterization [27, 51, 97], (3) quality control $[43,100]$, (4) chemotaxonomy/chemophenetics [66, 83], and (5) ecology-chemistry $[14,87]$.

Regarding the field of food sciences, metabolomics proved to be an important tool for regulatory compliance, processing, quality, and safety [22]. In a review, CevallosCevallos et al. [22] identified that the most common studies in food analysis were focused on fruits and vegetables. Recently, there is no doubt that metabolomics has the potential to play major roles in many aspects of food authenticity and traceability [28]. In this sense, several studies using metabolomic methods and analyses have been carried out to investigate food authenticity [21, 100] and [44] and characterization [54], to the determination of samples' geographical origin $[8,57]$, and to the separation/distinction of samples produced in different geographical origins [45, 98].

Based on the presented literature, an integrative review would gather the concepts, clarify the research scenario, constitute a scientific taxonomy, and propose insights for future studies. The next section explains how the integrative review was structured and conducted.

\section{Methods}

\section{Data collection}

This work is exploratory in nature since it aimed to show the interconnections between the marketing and metabolomics fields. To achieve this purpose, an integrative literature review was proposed based on published research articles. This approach has an important role in stimulating new research, because it can generate new frameworks and perspectives on a certain topic based on a review and synthesis of the representative literature [95].

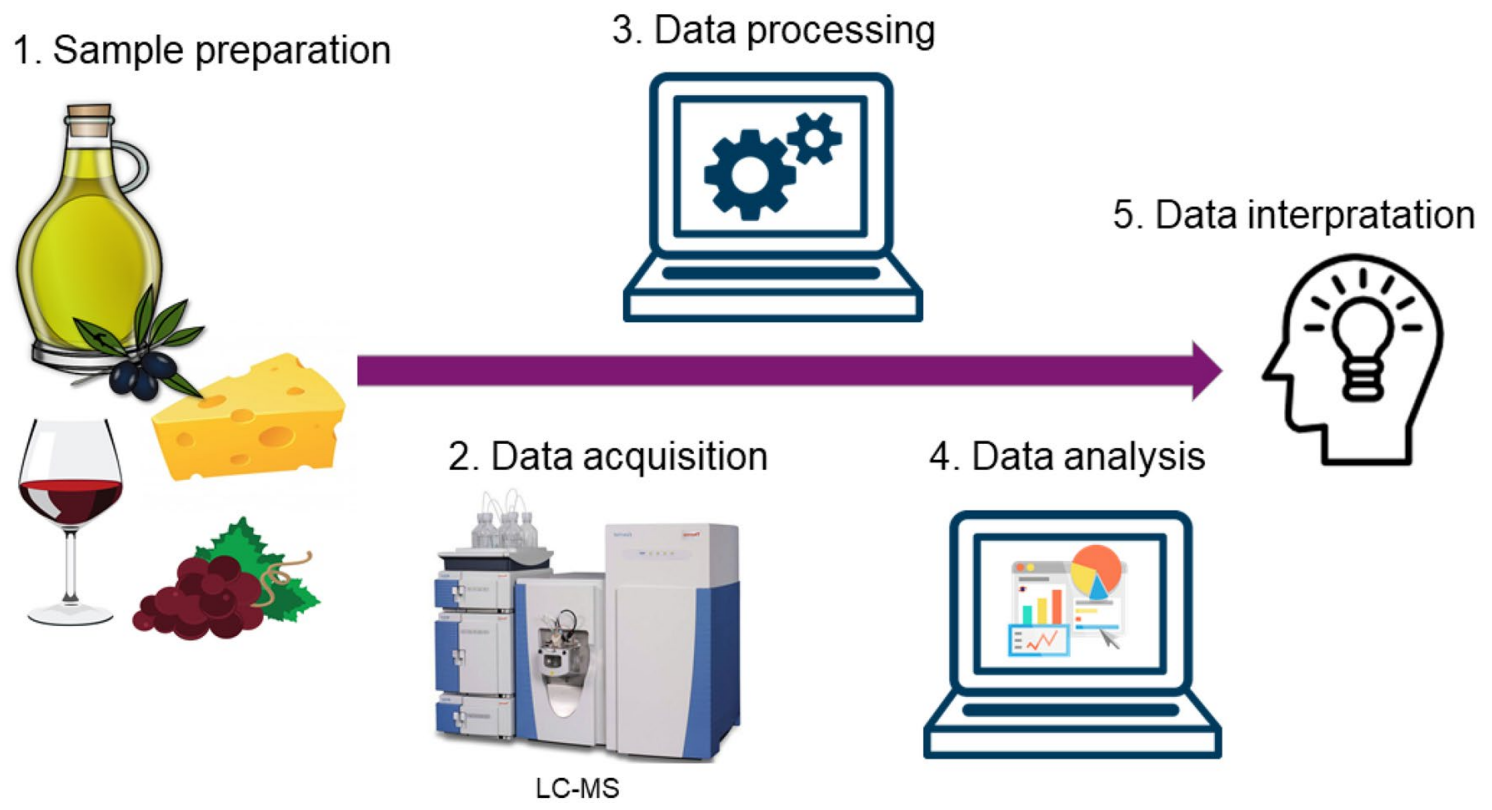

Fig. 1 Overview of a generalized metabolomics protocol. (1) Sample extraction must be defined, as it is a crucial step in selecting compounds. (2) The common workflow starts with separating and detecting molecules (for example by LC-MS). (3) The selected bigdata sets are processed. (4) Multivariate statistics can be used in data analysis. (5) It is up to the researcher to interpret the analyzes and make a diagnosis 
The database chosen for data collection was Scopus, since it has a rigorous and multidisciplinary indexer and a large corpus of academic articles that can be reached with precision using operators, time frames, and keywords [11]. Data were obtained in January 2021 and included the period from 2000 to 2020, since the first metabolomic studies on plants were published at the beginning of the twenty-first century [41].

The search strings were defined based on the main keywords in marketing literature (regarding the origin extrinsic cue) and metabolomics. The strings were searched in the title, summary, and keywords of articles, according to the following operationalization:

("metobolomics" OR "food metabolomics" OR "natural products metabolomics" OR "phytochemical studies" OR "metabolomic characterization") AND ("denomination of origin" OR "indication of origin" OR "geographical indication" OR "protected designation of origin" OR "protected geographical indication").

The search field chosen for the string search was "Article title, Abstract, Keywords." The following filters were applied to Scopus: articles from academic journals; English language only. Following an adapted process of identification, screening, eligibility, and inclusion from [68], Fig. 2 provides an overview of the analysis conducted.
The inclusion and exclusion criteria are presented in the Results and Discussion section.

\section{VOSviewer software}

After data collection, the VOSviewer software was used to verify and better visualize connections between data through graphs and maps [59]. Bibliometric maps were created on retrieved publications, using the VOSviewer software version 1.6.5.0 (freely available at http://www. vosviewer.com). Aiming to identify the main journals and most used keywords, analyses were based on the results presented by VOSviewer, which originates maps of distance, indicating the strength of relationships between items.

VOSviewer was specifically developed for creating, visualizing and exploring science's bibliometric maps, including bibliographic couplings, co-citations, and co-occurrences $[96,99]$. To graphically visualize the nodal network created by VOSviewer, the software uses two standardized weights, such as the number and total strength of links, thus the size of the nodes and the interconnecting lines between the nodes denote the relevance and strength of the nodes' links [33].
Fig. 2 Overview of analysis adapted from [68]

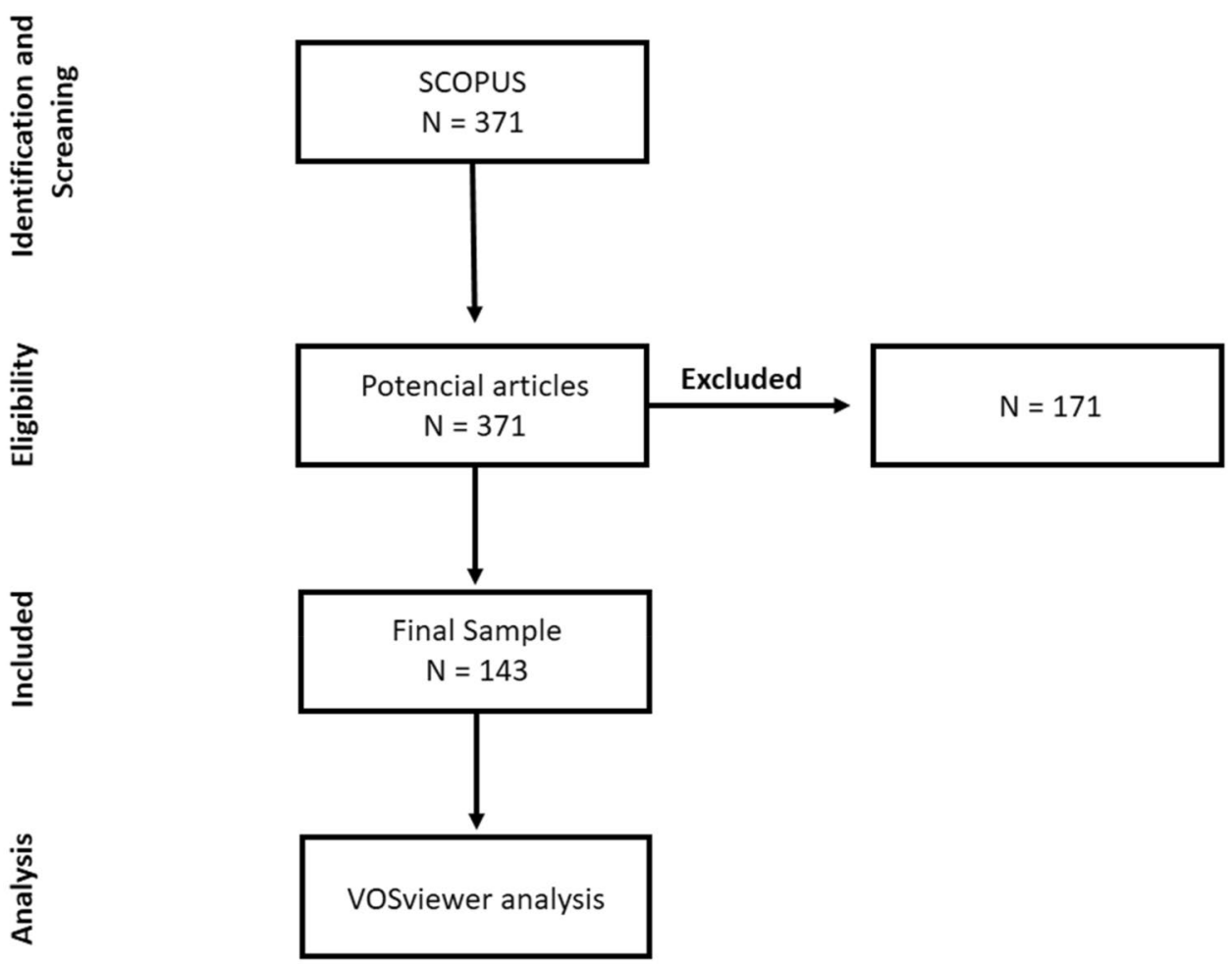




\section{Results and discussion}

Following the procedure presented, 314 articles were collected. First, data were tabulated according to product category, products' origins, year of publication, and if the study involves products with certification of origin or not (GI, PDO, PGI). After this, 171 articles were excluded due to the exclusion criteria: articles focused only on chemicalanalytical methods validation, articles with no relation to metabolomics approach, and articles with no mention/analysis of samples' origin. Thereafter, 143 articles composed the database (Supplementary Material I) used to verify: i. the number of publications by year; ii. the average number of publications by year; iii. the main journals with publications on the subjects; and iv. the trends in metabolomic studies involving products with the certification of GI, PDO, PGI.

The first article collected was published in 2009. Between 2009 and 2020, the average of publications on the Scopus platform was 13 publications per year. The largest number of publications was in 2019, with a total of 39 articles. Figure 3 shows the growth of publications on the subject over the years.

Based on the data set, the following theoretical gap is observed: no studies relating the topics "marketing" and "metabolomics" were found, either with theoretical or applied methods that use metabolomic tools to promote and guarantee a GI product, therefore, corroborating the ontoepistemological importance of the subject. This gap starts a novel scientific venue and a foundation for future research, which will ally metabolomics studies with marketing theory so that product certification, traceability, and promotion based on chemical compounds can be achieved.

There is ongoing growth in the number of publications in the chemistry area focused on products with certification of origin. One reason for that is the evolution of metabolomic techniques, which are cheaper and faster nowadays, consequently more accessible to researchers and laboratories.

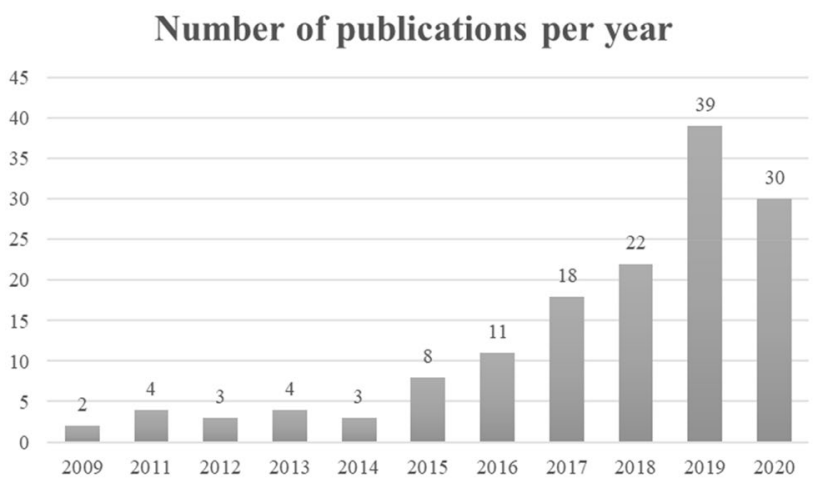

Fig. 3 Number of publications per year
Many of these studies misuse the terms of certification of origin (GI, PDO, PGI), and often there is no precise specification of the origin of the samples used. Consequently, the results could make researchers of the chemical field aware of the importance of correctly applying the terms related to certification of origin in their future works, mainly if there is the intention of sharing them with other stakeholders (e.g., producers, government, agricultural cooperatives).

It is important to note that the number of publications in 2020 did not follow the growth pattern seen in previous years. One possible cause is the COVID-19 pandemic that affected research around the world by the impossibility of cultivating and collecting samples in the field and attending to laboratories.

Studies indicate that the pandemic directly impacted academic publications with a decrease in the average time of analysis and acceptance of articles concerning the COVID19 pandemic, which were prioritized at the expense of articles not related to the topic [7, 34]. According to AvivReuven and Rosenfeld [7], international collaboration on research unrelated to COVID-19 slowed down during the pandemic crisis.

Figure 4 illustrates all 41 academic journals using density to relate them to the respective number of publications.

Sixteen journals corresponded to 83 of 108 publications found. The journals that published three or more articles are illustrated in Fig. 4. The journals that published more articles are, respectively: Food Chemistry (22), Journal of Agricultural and Food Chemistry (10), Food Research International (9). Together, they account for almost $38 \%$ of all articles. Most of the articles are concentrated in journals from chemistry and food fields, and none of them are from the marketing area. It is confirmed that a great part of these article analyzes samples with certification of origin. Consequently, chemical and biological results could be extended to other issues and discussions regarding marketing and consumer perspectives (i.e., management, promotion, and commercialization of GI/PDO/PGI products).

To identify the most used words, a keywords co-occurrence map is depicted in Fig. 5. The keywords co-occurrence map is based on analyzing the most frequent or important words found in the articles [18], referring to terms contained in the title and summary. From these words, 11 related to the format of the academic texts were excluded (i.e., article, procedures, analysis, multivariate analysis, compounds, etc.). The result is a map based on the following 23 words: chemistry, discriminant analysis, mass spectrometry, metabolomics, multivariate analysis, high-performance liquid chromatography, classification, chemometrics, Italy, nonhuman, geographical origins, geography, food analysis, proton nuclear magnetic resonance, metabolism, unclassified drug, authentication, wine, protected designation of origins, geographical origin, olive oil, geographic origin, quality control. 


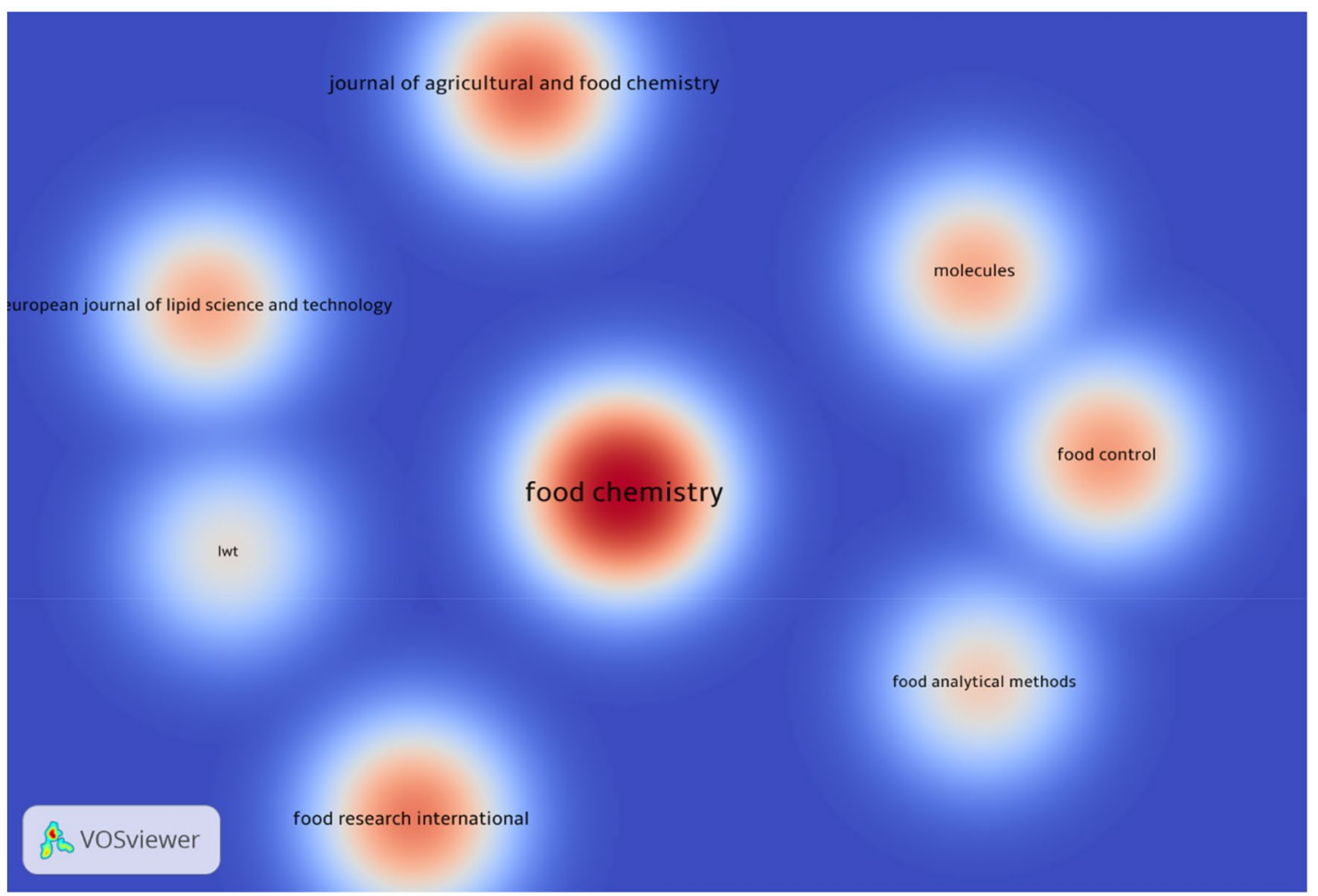

Fig. 4 Academic journals using density map

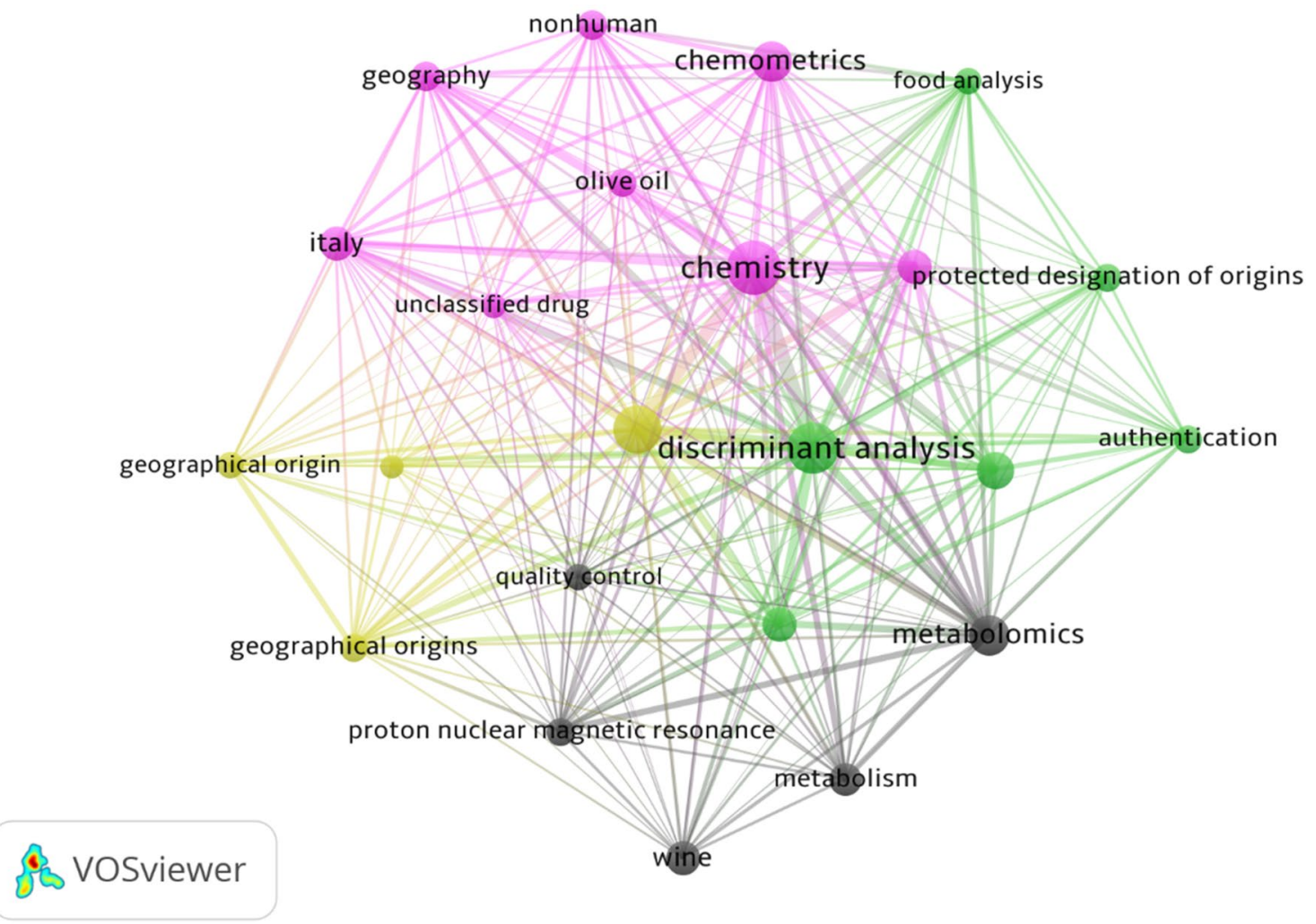

Fig. 5 The keywords co-occurrence map based on the most frequent or important words 
The keywords were categorized by year of publication (Fig. 6) to deepen the analysis. The VOSviewer software represents the years with the highest number of publications in a timeline between 2016 and 2018. However, articles from 2009 to 2020 are contained in this analysis. The most frequent keywords are in purple in Fig. 6, respectively: authentication, metabolomics, geographical origin, high-performance liquid chromatography, and wine.

Results of both co-occurrence maps (Figs. 5 and 6) provide guidance on the main discussions conducted in the last 20 years on metabolomics research using products with certification of origin.

Based on the analysis of abstracts and conclusions of all articles and on the keywords co-occurrence map, the main subthemes' taxonomic categorization is proposed: (1) chemical studies using products with no certification of origin, (2) chemical studies using products with certification of origin, (3) comparison of chemical composition between products with certification of origin from different countries, (4) comparison of chemical composition between products from different certified regions, (5) comparison of chemical composition between different sites within the same certified region, (6) comparison of chemical composition between products with and without certification of origin, and (7) chemical analysis to support the registration of a region as GI, PDO or PGI.
To provide a facilitator for research on products' metabolomics studies with certification of origin, Table 1 relates the proposed categories to the number of articles and a brief explanation about classification adopted.

The articles that consist of the first category, "chemical studies using products with no certification of origin," apply chemical analyses to products that are originated in a specific region or country, but the author does not state in any part of the article if that place has its origin certified. As an example of a study in this category, Wu et al. [102] analyzed wines from different countries and geographic regions, but the authors have not determined if there is certification of origin on the product. Similarly, Kalogiouri, Aalizadeh, and Thomaidis [55] confirm the excellent quality of Greek oils as consequences of local climatic and edaphic conditions, emphasizing the benefits that the characterization and authentication of Greek extra virgin olive oils based on cultivation and geographical origin could bring, a possibility of establishment of a country brand in the international market. Nevertheless, Kalogiouri et al. [55] do not indicate whether the analyzed products have certification of origin.

In the wine category, one of the most affected by fraud, adulteration and other misleading practices, the verification of product authenticity with chemical-analytical methods are necessary. For this reason, Springer [90] used multiclass chemometric strategies to classify and distinguish between German and non-German wine varieties. [63] have

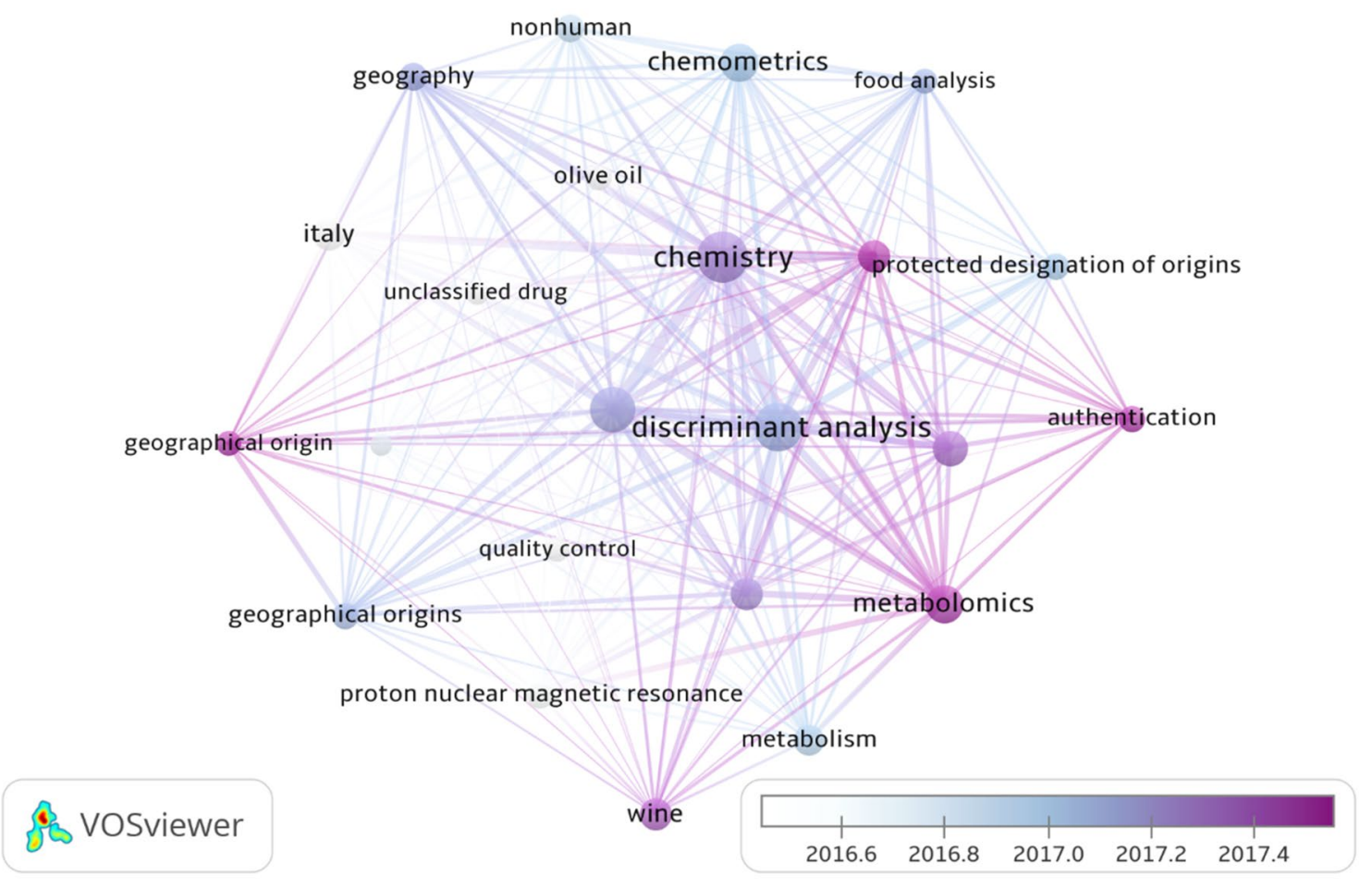

Fig. 6 The keywords co-occurrence map categorized by year of publication 
Table 1 Taxonomic categories, number of articles and a brief explanation about classification adopted

\begin{tabular}{|c|c|c|}
\hline Taxonomic categorization & $\begin{array}{l}\text { Number } \\
\text { of articles }\end{array}$ & Brief explanation \\
\hline Chemical studies using products with no certification of origin & 65 & $\begin{array}{l}\text { Studies with products of a specific country or region, although } \\
\text { the authors do not mention if the product analyzed has its } \\
\text { origin certified (GI, PDO, PDI). Wu et al. [102] }\end{array}$ \\
\hline Chemical studies using products with certification of origin & 26 & $\begin{array}{l}\text { Studies analyzing products with certification of origin (GI, PDO, } \\
\text { PDI) with the purpose of identification and quantification of } \\
\text { metabolites; or product authentication and traceability. Pascale } \\
\text { et al. [77] }\end{array}$ \\
\hline $\begin{array}{l}\text { Comparison of chemical composition between products with } \\
\text { certification of origin from different countries }\end{array}$ & 5 & $\begin{array}{l}\text { Studies comparing products from different countries. Authors } \\
\text { indicate the origin of the samples as certified (GI, PDO, PDI). } \\
\text { Arana et al. [4] }\end{array}$ \\
\hline $\begin{array}{l}\text { Comparison of chemical composition between products from } \\
\text { different certified regions }\end{array}$ & 15 & $\begin{array}{l}\text { Studies comparing two or more products from different certified } \\
\text { regions within the same country. Papotti et al. [76] }\end{array}$ \\
\hline $\begin{array}{l}\text { Comparison of chemical composition between different sites } \\
\text { within the same certified region }\end{array}$ & 10 & $\begin{array}{l}\text { Studies comparing products from different sites within the same } \\
\text { GI/PDO/PDI. [61] }\end{array}$ \\
\hline $\begin{array}{l}\text { Comparison of chemical composition between products with and } \\
\text { without certification of origin }\end{array}$ & 21 & $\begin{array}{l}\text { Studies comparing products from a certified region (GI, PDO, } \\
\text { PDI) with a similar from a non-certified region. Rocchetti et al. } \\
\text { [81] }\end{array}$ \\
\hline $\begin{array}{l}\text { Chemical analysis to support the registration of a region as GI, } \\
\text { PDO or PGI }\end{array}$ & 1 & $\begin{array}{l}\text { The authors confirm that the analyzed product comes from a } \\
\text { region that still has its name under legal process for registration } \\
\text { and that the research results could support it. Heude et al. [50] }\end{array}$ \\
\hline
\end{tabular}

classified 126 wines from Romania and France based on cultivar, geographical origin, and crop. The influence of the terroir was confirmed in the study, but the authors do not indicate whether part of the wine samples came from a certified region.

The second category, "chemical studies using products with certification of origin," addresses articles that adopt metabolomics approaches to identify the certified origin of the analyzed product. For instance, Pascale et al. [77] described chemical substances in peperoni di Senise peppers (Capsicum annuum L.), a European Union PGI. Napolitano et al. [70] identified 11 phenolic compounds of fresh and roasted hazelnut grains "Tonda di Giffoni", a PGI product from the region of Campania (Italy).

In categories 3, 4, 5, and 6, all authors identified the certified origin source for the samples. The third "comparison of chemical composition between products with certification of origin from different countries" taxonomic category encompasses studies similar to Arana et al. [4], with metabolomics techniques to discriminate Colombian coffees from foreigners' coffees, especially from neighboring countries. OlmoGarcia et al. [74], another example, adopted a metabolomic approach as a strategy to authenticate the declared origin of extra virgin olive oils. The analysis included samples from six different GIs from the Mediterranean and resulted in the discrimination and definition of distinct compositional patterns for each GI [74].

Studies comparing products with certification of origin that belonged to the same country, but different producing regions, were included in category 4 , "comparison of chemical composition between products from different certified regions." Papotti et al. [76] (comparison between three different PDO Lambrusco wines from Modena) and from Moyano et al. [69] (comparison of eight Spanish wines from different DOs) are examples of studies of this category. The results of this category's studies help to conclude that metabolomic methods are useful tools to determine volatile compounds in products, such as wines. Other studies focus on Grape marc, which is a by-product exploited by many wine producing countries because of its high levels of polyphenols, a compound that decreases the risk of chronic diseases. Alvarez-Casas et al. [3] studied the phenolic composition of grape marcs from five different Spanish certified regions aiming to characterize this important by-product. As a result, the authors found differences in the antioxidant capacity of the marc varieties, which is useful to market this product to consumers with a demand for more natural and functional additives in wines.

The unparalleled sensitivity of metabolomics methods can provide the specification of samples within the same site. The fifth taxonomic category, "comparison of chemical composition between different sites within the same certified region," includes studies similar to Lima et al. [61], which performed metabolomics in Portuguese cheeses from Serra da Estrela region and concluded that products from different producers were different (an extreme relevant conclusion for producers and consumers). Another study in this category demonstrates the "soil effect" in the biochemical composition of PDO Aleatico di Gradoli grapes and wines cultivated in the northern part of the Lazio region (central Italy) [30]. 
To prove environmental variability and to verify the relationship between soil and grape quality (the core of terroir definition), De Santis et al. [30] collected samples from five sub-areas of the region. Data confirmed that the identification of grapes and wines' biochemical parameters can be an indicator of oenological potential according to the origin.

The sixth category, "comparison of chemical composition between products with and without certification of origin," includes articles analogous to Rocchetti et al. [81] that determined chemical differences in the fingerprints of PDO Grana Padano cheeses and non-PDO "Grana type" cheeses. Similarly, Salzano et al. [85] analyzed 11 dairy products located in a DOP region and nine dairy products located in a non-DOP region, both in Italy. After data processing, PLS-DA graphs clearly differentiated samples of mozzarella milk PDO and non-PDO and identified which metabolites were discriminate to the separation. These discoveries are examples of articles that establish metabolomic methods as a powerful technology platform to determine authenticity and create protection for products with certifications of origin.

The last category, "chemical analysis to support the registration of a region as GI, PDO or PGI," considers studies like Heude et al. [50], which aimed to support Aquitaine's caviar producers to establish a PGI by defining the metabolomic profiles of the product. The authors developed multivariate statistical models to discriminate which caviar samples belonged to the region, attesting that the results are of great interest in the context of PGI registrations.

Another important finding is the high number of studies on certain product categories and countries. In detail, Table 2 organizes these articles by type of product studied, the corresponding number of certifications of origin in that category, and the samples' country of origin.

The product categories most used for analysis in metabolomics studies are oils, wines, cheeses, fruits, and vegetables. More than half of the samples studied have certification of origin (GI, PDO, or PGI). Origin cue has been attached to the first three product categories for a long time as a sign of quality and tradition $[9,60,79]$. Though, there has been an increase in studies of other product categories (i.e., spices) with a record in registration and communication of origin $[16,65]$.

According to the statements of Banks et al. [9] about wines, these products will be integrated into regional traditions in the near future, gradually becoming part of the place's references. The certification of origin of products produced by countries or regions with a recent history in producing them (i.e., Brazilian and Australian wines) are based mainly on demonstrating the benefits that these unconventional or exotic origins can add to the product. Based on the number of GIs and studies in certain product categories and regions, it can be said that origins that already have traditions in particular productions are now demonstrating interest in signaling it. (i.e., Chinese mushroom, rice, and vinegar, Iranian saffron).

Table 2 also shows that most studies focus on products of European origin, a place that has an ancient tradition in origin registration and the largest number of registered products. Another reason is the fact that many non-EU countries use EU legal systems for origin registration purposes, like Cambodia's Kampot pepper, which achieved the EU PGI title in 2016.
Table 2 Product studied, number of articles, samples' country of origin and corresponding number of certifications of origin in that category

\begin{tabular}{llll}
\hline Product category & $\begin{array}{l}\text { Number } \\
\text { of articles }\end{array}$ & Most analyzed products' countries & $\begin{array}{l}\text { Products with } \\
\text { origin certifica- } \\
\text { tion }\end{array}$ \\
\hline Oil & 30 & Italy (20), Spain (7), Tunisia (4), Greece (3) & 10 \\
Wine & 29 & Italy (8), Australia (7), France (5), Greece (5), Spain (5) & 18 \\
Cheese & 16 & Italy (7), Greece (4), Mexico (2), Portugal (2) & 12 \\
Fruit/Vegetable & 16 & Italy (7), Greece (3), China (2), Spain (2) & 9 \\
Coffee & 9 & Brazil (6), Colombia (5) & 3 \\
Nut & 9 & Italy (6), France (2), Germany (2) & 4 \\
Grain & 7 & Italy (3), Brazil (2), Canada (2) & 2 \\
Spice & 7 & Italy (5), China (1), Iran (1), Ucrania (1) & 4 \\
Tea & 5 & China (5) & 1 \\
Honey & 4 & Brazil (1), China (1), Marokko (1), Portugal (1) & 1 \\
Vinegar & 3 & Italy (1), Spain (1), China (1) & 2 \\
Medicinal Herb & 3 & China (2), Vietnam (1) & 0 \\
Seafood & 2 & France (1) \\
Beer & 1 & Czech Republic and Spain & in progress \\
Mushroom & 1 & China (1) & 0 \\
White Lotus Seed & 1 & China (1) & 0 \\
\hline
\end{tabular}


Italy appears as the most cited source in the studies of products that are already registered as GI and of those that are still not. Furthermore, the country is used as a source of products for studies in several food categories, confirming Italy's high level of expertise in origin certifications. Another fact is that most GI records in the world are concentrated in southern European countries: Italy, Spain, France, Greece, and Portugal. Together, these countries have more than $70 \%$ of EU GIs food registrations and $80 \%$ of EU GIs wine registrations [53]. The emphasis of studies on some countries can also be attributed to the fact that they represent the highest value of exports of GI products to non-EU countries [37, 38].

Figure 7, a VOSviewer map of co-authorship by countries, expresses the country's sphere size and position based on the number of studies the diversity of the co-authorships related to that country, which is a corroboration of the results presented in the column "Countries" of Table 2.

Concerning the agricultural products that were chosen as the object of study by researchers, the product categories with the most GI records (wines: 1616 records, cheeses: 248, and oils: 143) are the focus of most collected articles [39]. These products are also the most exported by the EU, therefore, they warrant legal protection and studies of authenticity and traceability. In part, reasons for the academic interest in these product categories can rely on economic data. Although research analyzes agricultural products and foodstuff with the use of metabolomic techniques, it can be noted based on results that the main goals of most studies are driven to the identification of chemical profiles to distinguish the product with registration of origin.
The importance and relevance of "-omics" studies were evidenced, especially in metabolomics, and for products with certifications of origin. The field is useful to demonstrate the effects of "country of origin" and "terroir" in chemical composition. In addition, it presents the possibility of establishing a fingerprint to authenticate that the analyzed product belongs to a certain region.

The articles used by the authors to exemplify each subcategory indicate that metabolomics techniques are powerful tools to be included within the GI system, and also be expanded to other economic sectors (e.g., tourism, culinary), since it presents chemical evidences to define product authenticity and typicality. Recent studies show the importance of differentiation strategy for food products (e.g., wine, cheese, olive oil) and its impact on the consumer decision process [10]. The utilization of metabolomic as product cue is a guarantee of the product's intrinsic value and a reasonable excuse for higher prices. It means that metabolomic gives real evidences of premium prices, validating terroir interferences (e.g. specific compounds or biomarkers identification).

For instance, wineries belonging to the German wine route could apply metabolomics techniques to prove wines' differentiation (e.g., based on wine chemical fingerprinting) and intrinsic characteristics. In this way, smaller and new wine producers within that region have a chance to compete with already established and renowned wine producers, utilizing chemical data to add value to their product and therefore to attract tourists. Also, new wine blends could be promoted based on metabolomics. Ingredients with verified chemical attributes (evidenced through metabolomics tools)

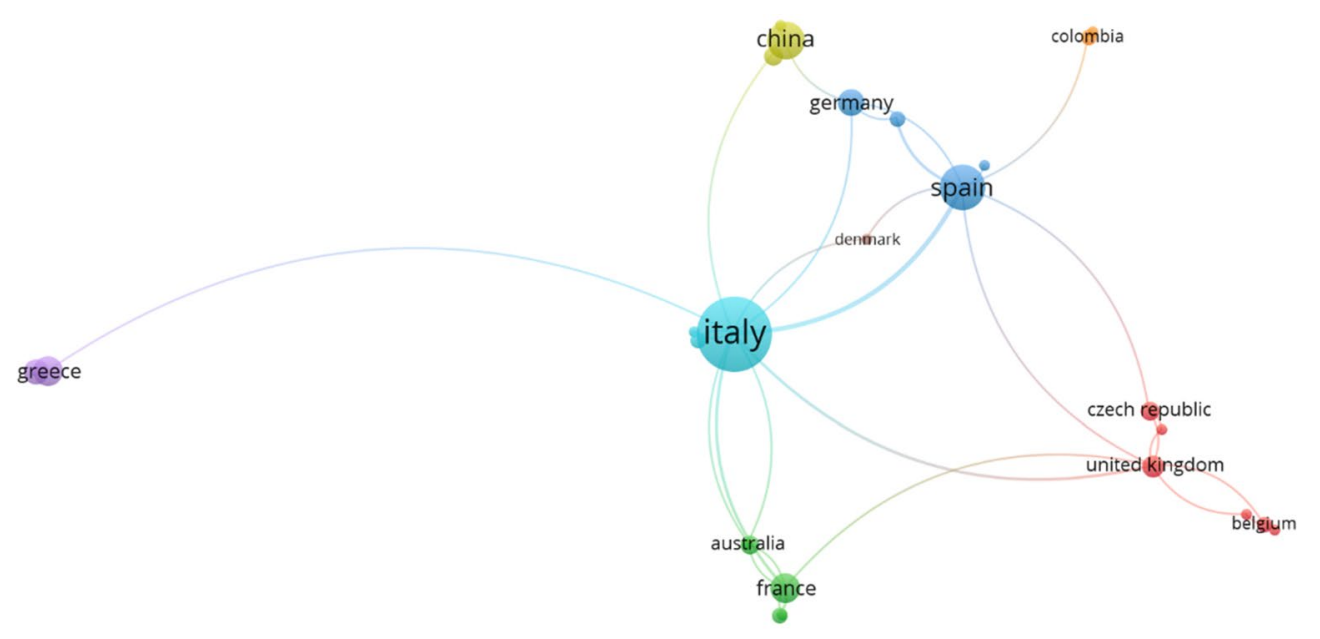

WOSviewer

Fig. 7 Map of co-authorship by countries 
could have their culinary use promoted, such as restaurants offering dishes with local ingredients (e.g., cheese, olive oil, mushroom, saffron) can present their chemical fingerprints as a rational proof of authenticity, typicality and unique properties. This strategy could also foster local tourism, contributing to the place development.

New ventures and applications for metabolomic studies are established once marketing purposes are combined. For instance, chemical profiles derived from metabolomics studies could compose a fingerprint system for the authentication of agri-food products, making it easier and faster for public agencies to register new GIs. Metabolomic can also be used to detect product fraud and free-riders who take advantage of GI's name, image, and reputation to add value to products that were not produced in the certified place. In these cases, certified food producing places can apply metabolomics techniques to preserve place image and reputation.

In addition, the metabolomic approach can be used as a marketing tool by producers to promote the quality of their products further, indicating chemical evidence as proof of the effects of terroir and savoir-faire in the final product. Gradually, consumers could be educated to understand certain metabolomic information and relate it to the intrinsic attributes of the product, similar to the knowledge that regular wine consumers acquired about wine compositions and the sensory characteristics related to them (i.e., the presence of tannins associated with astringency, other phenolics associated to color, or volatiles related to flavor). Based on metabolomic studies, organoleptic nuances could be explored and promoted to penetrate existing market segments and enter into new ones.

Specifically, the wine industry presents a clear demonstration of how metabolomics can be used for marketing purposes. For instance, wine quality is influenced by consumer's expectations and sensory experiences [89]. According to Sherman et al. [89], sensory experience is based on wine's intrinsic features, defined mainly by aroma, taste, and mouthfeel. In other words, wine quality is drastically influenced by consumer perceptions of the product's metabolites. As proved by Arapitsas et al. [6] in a study with 11 types of red wines (Aglianico, Cannonau, Corvina, Montepulciano, Nebbiolo, Nerello, Primitivo, Raboso, Sagrantino, Sangiovese e Teroldego) from 12 locations in Italy, genotypically similar grapes, but from different regions, result in wines of distinct chemical compositions. Using liquid chromatography coupled with mass spectrometry, the authors prove the similarities among the analyzed cultivars, identifying biomarkers for each origin studied and a characterization of each "cultivar-terroir" combination. Such metabolomic analysis can be applied to a certain GI's product with the aim to confirm that it is indeed different from other from specialized producing regions, and that presents a unique sensory experience based on its own chemical fingerprint. Moreover, authenticity and typicality can be proven on the basis of chemical data and then be used for terroir promotion.

In other words, metabolomics techniques scientifically prove that products originated in different regions are distinct due to their local particularities (e.g., altitude, climate, producing methods, soil, etc.). Hence, food producers can rely on metabolomics reports, produced by specialized scientists, to indicate the link between place and product, and promote the product's uniqueness. The metabolomic report would point out which substances can serve as product biomarkers (i.e., proof of place-product link), confirming product authenticity. Arapitsas et al. [6] proved with metabolomics techniques that, despite various similarities, 11 grape cultivars produced in different regions of Italy are very specific in terms of metabolomes. This kind of study is a starting point for producers, associations, and GI managers to product differentiation.

Following the categorization proposed and our analysis, it was possible to identify the correlations between the researched scientific fields. In this way, Fig. 8 summarizes the main topics of our discussion, illustrating the possibilities of metabolomics in the marketing of GIs.

\section{Conclusions}

The results of the analysis in VOSviewer software and the integrative literature review support our main theoretical contribution: an original taxonomic categorization related to metabolomics studies using products with GI/PDO/PGI in the last 20 years. The presented results shed light on the state of the art that concerns the combination of metabolomics and marketing areas. The taxonomy created can be used as a facilitator and guide for future studies in this new venue of research. Metabolomics can provide a chemical fingerprint system that could be applied to GIs, optimizing registration processes. It is also a potential marketing tool once the chemical fingerprint is linked to the product's intrinsic attributes and quality and applied to reach different market segments. The establishment and communication of the product's chemical profile can increase consumers' confidence. Chemical differences and nuances can be transformed into competitive advantage, enhancing consumer communication programs and making it possible to deepen existing market segments and exploring new niches.

The main limitation of the research relates to the selection of one database, Scopus, and the analysis of studies only in the English language. It was confirmed that metabolomics is a valuable tool with great potential for the marketing field, and, to explore possible benefits, further studies are needed. Our suggestions for future research relating to marketing and metabolomics are metabolomics 


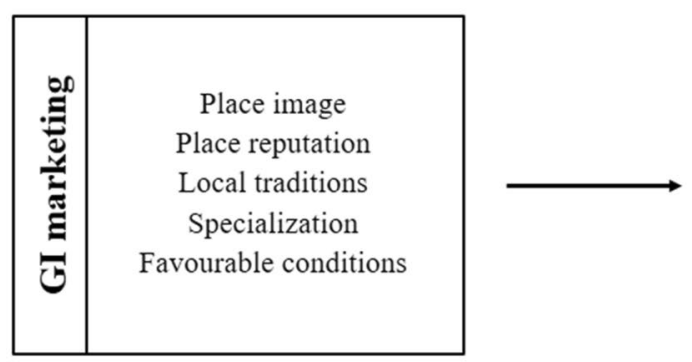

\begin{tabular}{|c|c|}
\hline & Metodological \\
& Rigor \\
& Replicability \\
& Reliability \\
Robustness
\end{tabular}

Fig. 8 Overview of results

studies focused on more specific marketing themes (i.e., consumer segmentation, product development, labeling, branding); the use of other "omics" to contribute to the chemical profile resulted from metabolomics techniques (i.e., [93] and the Greek "omics" consortium); studies on consumer education and acceptance of metabolomics profile and chemical information availability; studies on the possible contribution of metabolomics data to economic activities related to GIs (i.e., tourism).

Supplementary Information The online version contains supplementary material available at https://doi.org/10.1007/s00217-021-03782-2.

Author contributions All the authors have read, approved, and made substantial contributions for the manuscript.

Funding Not applicable.

Availability of data and materials Data are available at Supplementary Material.

Code availability Not applicable.

\section{Declarations}

Conflict of interest On behalf of all authors, the corresponding author declares that there is no conflict of interest.
Consent for publication We, the author and co-authors, state that this article is original and has not been submitted for publication in any other journal, whether in part or in its entirety. We assign the copyright of the referred article to European Food Research and Technology as well as the consent for publication.

Compliance with Ethics requirements This research does not involve human/animal tests. It is a Literature Review based on online data (articles).

Ethics approval Not applicable.

Consent to participate Not applicable.

\section{References}

1. Agostino M, Trivieri F (2016) European wines exports towards emerging markets. The role of geographical identity. J Ind Compet Trade 16(2):233-256. https://doi.org/10.1007/ s10842-015-0210-Z

2. Albuquerque TG, Oliveira MBP, Costa HS (2018) 25 years of European Union (EU) quality schemes for agricultural products and foodstuffs across EU Member States. J Sci Food Agric 98(7):2475-2489. https://doi.org/10.1002/jsfa.8811

3. Alvarez-Casas M, Pájaro M, Lores M, Garcia-Jares C (2016) Characterization of grape marcs from native and foreign white varieties grown in northwestern Spain by their polyphenolic 
composition and antioxidant activity. Eur Food Res Technol 242:655-665. https://doi.org/10.1007/s00217-015-2573-0

4. Arana VA, Medina J, Alarcon R, Moreno E, Heintz L, Schäfer H, Wist J (2015) Coffee's country of origin determined by NMR: the Colombian case. Food Chem 175:500-506. https://doi.org/ 10.1016/j.foodchem.2014.11.160

5. Arana VA, Medina J, Esseiva P, Pazos D, Wist J (2016) Classification of coffee beans by GC-C-IRMS, GC-MS, and ${ }^{1} \mathrm{H}-\mathrm{NMR}$. J Anal Methods Chem 2016:8564584. https://doi.org/10.1155/ 2016/8564584

6. Arapitsas P, Ugliano M, Marangon M, Piombino P, Rolle L, Gerbi V, Versari A, Mattivi F (2020) Use of untargeted liquid chromatography-mass spectrometry metabolome to discriminate Italian monovarietal red wines, produced in their different terroirs. J Agric Food Chem 68(47):13353-13366. https://doi.org/ 10.1021/acs.jafc.0c00879

7. Aviv-Reuven S, Rosenfeld A (2020) Publication patterns' changes due to the COVID-19 Pandemic: a longitudinal and short-term scientometric analysis. https://arxiv.org/abs/2010. 02594

8. Bachmann R, Klockmann S, Haerdter J, Fischer M, Hackl T (2018) ${ }^{1} \mathrm{H}$ NMR spectroscopy for determination of the geographical origin of hazelnuts. J Agric Food Chem 66(44):1187311879. https://doi.org/10.1021/acs.jafc.8b03724

9. Banks G, Kelly S, Lewis N, Sharpe S (2007) Place 'From One Glance': the use of place in the marketing of New Zealand and Australian wines. Aust Geogr 38(1):15-35. https://doi.org/10. 1080/00049180601175840

10. Barber M, Sung B, Lee S, Cheah I (2020) Exploring the influence of novelty and authenticity in wine consumption: the moderating effect of regionality and price. Int J Wine Bus Res. https://doi. org/10.1108/IJWBR-06-2020-0031

11. Bergman EML (2012) Finding citations to social work literature: The relative benefits of using Web of Science, Scopus, or Google Scholar. J Acad Librariansh 38(6):370-379. https://doi.org/10. 1016/j.acalib.2012.08.002

12. Blazenovic I, Kind T, Sa MR, Ji J, Vaniya A, Wancewicz B, Roberts BS, Torbašinović H, Lee T, Mehta SS, Showalter MR, Songm H, Kwok J, Jahn D, Kim J, Fiehn O (2019) Structure annotation of all mass spectra in untargeted metabolomics. Anal Chem 91(3):2155-2162. https://doi.org/10.1021/acs.analchem. $8 \mathrm{~b} 04698$

13. Boukid F, Abbattangelo S, Carini E, Marseglia A, Caligiani A, Vittadini E (2019) Geographical origin discrimination of Pistachio (Pistacia vera L.) through combined analysis of physical and chemical features. Eur Food Res Technol 245(1):143-150. https://doi.org/10.1007/s00217-018-3146-9

14. Budzinski IGF, Moon DH, Morosini JS, Lindén P, Bragattom J, Morotiz T, Labate CA (2016) Integrated analysis of gene expression from carbon metabolism, proteome and metabolome, reveals altered primary metabolism in Eucalyptus grandis bark, in response to seasonal variation. BMC Plant Biol 16:149. https:// doi.org/10.1186/s12870-016-0839-8

15. Bueno P, Lopes NP (2020) Metabolomics to characterize adaptive and signaling responses in legume crops under abiotic stresses. ACS Omega 5(4):1752-1763. https://doi.org/10.1021/ acsomega.9b03668

16. Brunner M, Katona R, Stefánka Z, Prohaska T (2010) Determination of the geographical origin of processed spice using multielement and isotopic pattern on the example of Szegedi paprika. Eur Food Res Technol 231(4):623-634. https://doi.org/10.1007/ s00217-010-1314-7

17. Brunetti AE, CarnevaleNeto F, Vera MC, Taboada C, Pavarini DP, Bauermeister A, Lopes NP (2018) An integrative omics perspective for the analysis of chemical signals in ecological interactions. Chem Soc Rev 47(5):1574-1591. https://doi.org/ $10.1039 / \mathrm{c} 7 \mathrm{cs} 00368 \mathrm{~d}$

18. Callon M, Courtial JP, Turner WA, Bauin S (1983) From translations to problematic networks: an introduction to co-word analysis. Soc Sci Inf 22(2):191-235. https://doi.org/10.1177/05390 1883022002003

19. Casoti R, Guiraldelli A, Freitas JA, Santos FA, Da Costa FB (2018) Topics on metabolomics. In: Diniz M, De FFM (eds) Natural products and drug discovery: from pharmacochemistry to pharmacological. Editora UFPB, João Pessoa, pp 82-125

20. Castro VA, Giraldi JDME (2018) Shared brands and sustainable competitive advantage in the Brazilian wine sector. Int J Wine Bus Res 30(2):243-259. https://doi.org/10.1108/ IJWBR-04-2017-0019

21. Cecchi L, Migliorini M, Giambanelli E, Rossetti A, Cane A, Mulinacci N, Melani F (2020) Authentication of the geographical origin of virgin olive oils from the main worldwide producing countries: a new combination of HS-SPME-GC-MS analysis of volatile compounds and chemometrics applied to 1217 samples. Food Control 112:107156. https://doi.org/10. 1016/j.foodcont.2020.107156

22. Cevallos-Cevallos JM, Reyes-De-Corcuera JI, Etxeberria E, Danyluk MD, Rodrick GE (2009) Metabolomic analysis in food science: a review. Trends Food Sci Technol 20(1112):557-566. https://doi.org/10.1016/j.tifs.2009.07.002

23. Chagas-Paula DA, Oliveira TB, Zhang T, Edrada-Ebel R, Da Costa FB (2015) Prediction of anti-inflammatory plants and discovery of their biomarkers by machine learning algorithms and metabolomic studies. Planta Med 81(06):450-458. https:// doi.org/10.1055/s-0034-1396206

24. Charters S, Spielmann N, Babin BJ (2017) The nature and value of terroir products. Eur J Mark 51(4):748-771. https:// doi.org/10.1108/EJM-06-2015-0330

25. Chibli LA, Rosa AL, Nonato MC, Da Costa FB (2019) Untargeted LC-MS metabolomic studies of Asteraceae species to discover inhibitors of Leishmania major dihydroorotate dehydrogenase. Metabolomics 15(4):59. https://doi.org/10.1007/ s11306-019-1520-7

26. Chilla T, Fink B, Balling R, Reitmeier S, Schober K (2020) The EU food label 'Protected Geographical Indication': economic implications and their spatial dimension. Sustainability 12(14):5503. https://doi.org/10.3390/su12145503

27. Coutinho ID, Baker JM, Ward JL, Beale MH, Creste S, Cavalheiro AJ (2016) Metabolite profiling of sugarcane genotypes and identification of flavonoid glycosides and phenolic acids. $\mathbf{J}$ Agric Food Chem 64(21):4198-4206. https://doi.org/10.1021/ acs.jafc. $6 \mathrm{~b} 01210$

28. Cubero-Leon E, Peñalver R, Maquet A (2014) Review on metabolomics for food authentication. Food Res Int 60:95-107. https://doi.org/10.1016/j.foodres.2013.11.041

29. de Oliveira Dembogurski DS, Trentin DS, Boaretto AG, Rigo GV, da Silva RC, Tasca T, Macedo AJ, Carollo CA, Silva DB (2018) Brown propolis-metabolomic innovative approach to determine compounds capable of killing Staphylococcus aureus biofilm and Trichomonas vaginalis. Food Res Int 111:661-673. https://doi.org/10.1016/j.foodres.2018.05.033

30. De Santis D, Frangipane MT, Brunori E, Cirigliano P, Biasi $R$ (2017) Biochemical markers for enological potentiality in a grapevine aromatic variety under different soil types. Am J Enol Vitic 68(1):100-111. https://doi.org/10.5344/ajev.2016.15123

31. Dias C, Mendes L (2018) Protected designation of origin (PDO), protected geographical indication (PGI) and traditional speciality guaranteed (TSG): a bibiliometric analysis. Food Res Int 103:492-508. https://doi.org/10.1016/j.foodres.2017.09.059

32. Dinnie K (2015) Nation branding: concepts, issues, practice. Routledge, Amsterdam 
33. Donthu N, Kumar S, Pattnaik D (2020) Forty-five years of journal of business research: a bibliometric analysis. J Bus Res 109:1-14. https://doi.org/10.1016/j.jbusres.2019.10.039

34. Else H (2020) How a torrent of COVID science changed research publishing - in seven charts. Nature 588(7839):553. https://doi. org/10.1038/d41586-020-03564-y

35. Esslinger S, Riedl J, Fauhl-Hassek C (2014) Potential and limitations of non-targeted fingerprinting for authentication of food in official control. Food Res Int 60:189-204. https://doi.org/10. 1016/j.foodres.2013.10.015

36. European Commission (2019) €200 million to promote European agri-food products in and outside the EU. https://ec. europa.eu/commission/presscorner/detail/en/IP_19_6287. Accessed 11 Feb 2021

37. European Commission (2020) Study on economic value of EU quality schemes, geographical indications (GIs) and traditional specialities guaranteed (TSGs): final report. [online] op.europa.eu. https://op.europa.eu/en/publication-detail/-/publi cation/a7281794-7ebe-11ea-aea8-01aa75ed71a1. Accessed 11 Feb 2021

38. European Commission (2020) Geographical indications: a European treasure worth $€ 75$ billion. https://ec.europa.eu/commi ssion/presscorner/detail/en/IP_20_683. Accessed 11 Feb 2021

39. European Commission (2021) eAmbrosia: the EU geographical indications register. https://ec.europa.eu/info/food-farming-fishe ries/food-safety-and-quality/certification/quality-labels/geogr aphical-indications-register/. Accessed 12 Feb 2021

40. Fernández-Ferrín P, Bande B, Galán-Ladero MM, Martín-Consuegra D, Díaz E, Castro-González S (2019) Geographical indication food products and ethnocentric tendencies: the importance of proximity, tradition, and ethnicity. J Clean Prod 241:118210. https://doi.org/10.1016/j.jclepro.2019.118210

41. Fiehn O, Kopka J, Dörmann P, Altmann T, Trethewey RN, Willmitzer L (2000) Metabolite profiling for plant functional genomics. Nat Biotechnol 18(11):1157-1161. https://doi.org/10.1038/ 81137

42. Fiehn O (2002) Metabolomics: the link between genotypes and phenotypes. Plant Mol Biol 48:155-171. https://doi.org/10. 1023/A:1013713905833

43. Fiehn O, Wohlgemuth G, Scholz M, Kind T, Lee DY, Lu Y, Moon S, Nikolau B (2008) Quality control for plant metabolomics: reporting MSI-compliant studies. Plant J 53(4):691-704. https://doi.org/10.1111/j.1365-313X.2007.03387.x

44. Fotakis C, Zervou M (2016) NMR metabolic fingerprinting and chemometrics driven authentication of Greek grape marc spirits. Food Chem 196:760-768. https://doi.org/10.1016/j.foodchem. 2015.10.002

45. Ghisoni S, Lucini L, Angilletta F, Rocchetti G, Farinelli D, Tombesi S, Trevisan M (2019) Discrimination of extra-virginolive oils from different cultivars and geographical origins by untargeted metabolomics. Food Res Int 121:746-753. https:// doi.org/10.1016/j.foodres.2018.12.052

46. Gumus ZP, Celenk VU, Tekin S, Yurdakul O, Ertas H (2017) Determination of trace elements and stable carbon isotope ratios in virgin olive oils from Western Turkey to authenticate geographical origin with a chemometric approach. Eur Food Res Technol 243(10):1719-1727. https://doi.org/10.1007/ s00217-017-2876-4

47. Grunert KG, Aachmann K (2016) Consumer reactions to the use of EU quality labels on food products: a review of the literature. Food Control 59:178-187. https://doi.org/10.1016/j.foodcont. 2015.05.021

48. Harborne JB (1993) Introduction to ecological biochemistry. Gulf Professional Publishing, Oxford
49. Härtel I, Zhong L (2018) The right of geographical indications of agricultural products and food. Handbook of agri-food law in China, Germany, European Union. Springer, Cham, pp 611-641

50. Heude C, Elbayed K, Jezequel T, Fanuel M, Lugan R, Heintz D, Benoit P, Piotto M (2016) Metabolic characterization of caviar specimens by $1 \mathrm{H}$ NMR spectroscopy: towards caviar authenticity and integrity. Food Anal Methods 9(12):3428-3438. https:// doi.org/10.1007/s12161-016-0540-4

51. Hoffmann JF, Carvalho IR, Barbieri RL, Rombaldi CV, Chaves FC (2017) Butia spp. (Arecaceae) LC-MS-based metabolomics for species and geographical origin discrimination. J Agric Food Chem 65(2):523-532. https://doi.org/10.1021/acs.jafc.6b03203

52. Holmes E, Wilson ID, Nicholson JK (2008) Metabolic phenotyping in health and disease. Cell 134(5):714-717. https://doi.org/ 10.1016/j.cell.2008.08.026

53. Huysmans M, Swinnen J (2019) No terroir in the cold? A note on the geography of geographical indications. J Agric Econ 70(2):550-559. https://doi.org/10.1111/1477-9552.12328

54. Ingallina $C$, Cerreto A, Mannina L, Circi S, Vista S, Capitani D, Spano M, Sobolev AP, Marini F (2019) Extra-virgin olive oils from nine Italian regions: an ${ }^{1} \mathrm{H}$ NMR-chemometric characterization. Metabolites 9(4):65. https://doi.org/10.3390/metabo9040 065

55. Kalogiouri NP, Aalizadeh R, Thomaidis NS (2018) Application of an advanced and wide scope non-target screening workflow with LC-ESI-QTOF-MS and chemometrics for the classification of the Greek olive oil varieties. Food Chem 256:53-61. https:// doi.org/10.1016/j.foodchem.2018.02.101

56. Kim HK, Verpoorte R (2010) Sample preparation for plant metabolomics. Phytochem Anal 21(1):4-13. https://doi.org/10. 1002/pca. 1188

57. Klare J, Rurik M, Rottmann E, Bollen A, Kohlbacher O, Fischer M, Hackl T (2020) Determination of the geographical origin of Asparagus officinalis L. by $1 \mathrm{H}$ NMR Spectroscopy. J Agric Food Chem 68(49):14353-14363. https://doi.org/10.1021/acs. jafc.0c05642

58. Kohls RL, Uhl JN (2002) Marketing of agricultural products, 9th edn. Prentice-Hall Inc., London

59. Laengle SS, Modak NM, MerigóLindahl J, ZuritaAlarcón G (2018) Twenty-five years of group decision and negotiation: a bibliometric overview. Group Decis Negot 27(4):505-542. https://doi.org/10.1007/s10726-018-9582-x

60. Licitra G (2010) World wide traditional cheeses: banned for business? Dairy Sci Technol 90(4):357-374. https://doi.org/10.1051/ dst $/ 2010016$

61. Lima MR, Bahri H, Morais JS, Veloso AC, Fontes L, Lemos ET, Peres AM (2019) AssessingSerra da Estrela PDO cheeses' originproduction date using fatty acids profiles. J Food Measur Charact 13(4):2988-2997. https://doi.org/10.1007/s11694-019-00219-z

62. Luceri B, Latusi S, Zerbini C (2016) Product versus region of origin: which wins in consumer persuasion? Br Food J 118(9):2157-2170. https://doi.org/10.1108/BFJ-01-2016-0035

63. Magdas DA, Cozar BI, Feher I, Guyon F, Dehelean A, Pinzaru SC (2019) Testing the limits of FT-Raman spectroscopy for wine authentication: cultivar, geographical origin, vintage and terroir effect influence. Sci Rep 9:19954. https://doi.org/10.1038/ s41598-019-56467-y

64. Mannu A, Karabagias IK, Di Pietro ME, Baldino S, Karabagias VK, Badeka AV (2020) ${ }^{13}$ C NMR-based chemical fingerprint for the varietal and geographical discrimination of wines. Foods 9(8):1040. https://doi.org/10.3390/foods9081040

65. Marie-Vivien D, Vagneron I (2017) One size fits all or tailormade? Building appropriate certification systems for geographical indications in Southeast Asia. World Food Policy 3(2-1):105-126. https://doi.org/10.18278/wfp.3.2.4.1.6 
66. Martucci MEP, De Vos RCH, Carollo CA, Gobbo-Neto L (2014) Metabolomics as a potential chemotaxonomical tool: application in the genus Vernonia schreb. PLoS ONE 9(4):e93149. https:// doi.org/10.1371/journal.pone.0093149

67. Mele MA, Kang HM, Lee YT, Islam MZ (2020) Grape terpenoids: flavor importance, genetic regulation, and future potential. Crit Rev Food Sci Nutr. https://doi.org/10.1080/10408398.2020. 1760203

68. Moher D, Liberati A, Tetzlaff J, Altman DG, The PRISMA Group (2009) Preferred Reporting Items for Systematic Reviews and Meta-Analyses: ThePRISMA Statement. PLoS Med 6(7): e1000097. https://doi.org/10.1371/journal.pmed.1000097

69. Moyano L, Serratosa MP, Marquez A, Zea L (2019) Optimization and validation of a DHS-TD-GC-MS method to wineomics studies. Talanta 192:301-307. https://doi.org/10.1016/j.talanta. 2018.09.032

70. Napolitano A, Cerulli A, Pizza C, Piacente S (2018) Multiclass polar lipid profiling in fresh and roasted hazelnut (Corylus avellana cultivar "Tonda di Giffoni”) by LC-ESI/LTQOrbitrap/MS/MS ${ }^{\mathrm{n}}$. Food Chem 269:125-135. https://doi.org/10. 1016/j.foodchem.2018.06.121

71. Nicholson JK, Lindon JC, Holmes E (1999) 'Metabonomics': understanding the metabolic responses of living systems to pathophysiological stimuli via multivariate statistical analysis of biological NMR spectroscopic data. Xenobiotica 29(11):1181-1189. https://doi.org/10.1080/004982599238047

72. Ocvirk M, Grdadolnik J, Košir IJ (2016) Determination of the botanical origin of hops (Humulus lupulus L.) using different analytical techniques in combination with statistical methods. $\mathrm{J}$ Inst Brew 122(3):452-461. https://doi.org/10.1002/jib.343

73. Oliver SG, Winson MK, Kell DB, Baganz F (1998) Systematic functional analysis of the yeast genome. Trends Biotechnol 16(9):373-378. https://doi.org/10.1016/S0167-7799(98)01214-1

74. Olmo-García L, Wendt K, Kessler N, Bajoub A, FernándezGutiérrez A, Baessmann C, Carrasco-Pancorbo A (2019) Exploring the capability of LC-MS and GC-MS multi-class methods to discriminate virgin olive oils from different geographical indications and to identify potential origin markers. Eur J Lipid Sci Technol 121(3):1800336. https://doi.org/10.1002/ejlt.201800336

75. Padilla-González GF, Diazgranados M, Da Costa FB (2017) Biogeography shaped the metabolome of the genus Espeletia: a phytochemical perspective on an Andean adaptive radiation. Sci Rep 7(1):1-11. https://doi.org/10.1038/s41598-017-09431-7

76. Papotti G, Bertelli D, Graziosi R, Silvestri M, Bertacchini L, Durante C, Plessi M (2013) Application of one- and two-dimensional NMR spectroscopy for the characterization of protected designation of origin Lambrusco wines of Modena. J Agric Food Chem 61(8):1741-1746. https://doi.org/10.1021/jf302728b

77. Pascale R, Acquavia MA, Cataldi TRI, Onzo A, Coviello D, Bufo SA, Scrano L, Ciriello R, Guerrieri A, Bianco G (2020) Profiling of quercetin glycosides and acyl glycosides in sun-dried peperoni di Senise peppers (Capsicum annuum L.) by a combination of LC-ESI(-)-MS/MS and polarity prediction in reversed-phase separations. Anal Bioanal Chem 412:3005-3015. https://doi. org/10.1007/s00216-020-02547-2

78. Quiñones-Ruiz XF, Penker M, Belletti G, Marescotti A, Scaramuzzi S, Barzini E, Pircher M, Leitgeb F, Samper-Gartner LF (2016) Insights into the black box of collective efforts for the registration of geographical indications. Land Use Policy 57:103116. https://doi.org/10.1016/j.landusepol.2016.05.021

79. Renna M, Rinaldi VA, Gonnella M (2015) The Mediterranean Diet between traditional foods and human health: the culinary example of Puglia (Southern Italy). Int J Gastron Food Sci 2(2):63-71. https://doi.org/10.1016/j.ijgfs.2014.12.001

80. Ríos-Reina R, Callejón RM, Savorani F, Amigo JM, Cocchi M (2019) Data fusion approaches in spectroscopic characterization and classification of PDO wine vinegars. Talanta 198:560-572. https://doi.org/10.1016/j.talanta.2019.01.100

81. Rocchetti G, Lucini L, Gallo A, Masoero F, Trevisan M, Giuberti G (2018) Untargeted metabolomics reveals differences in chemical fingerprints between PDO and non-PDO Grana Padano cheeses. Food Res Int 113:407-413. https://doi.org/10.1016/j. foodres.2018.07.029

82. Rupprecht CD, Fujiyoshi L, McGreevy SR, Tayasu I (2020) Trust me? Consumer trust in expert information on food product labels. Food Chem Toxicol 137:111170. https://doi.org/10.1016/j.fct. 2020.111170

83. Sadgrove NJ, Telford IR, Padilla-González GF, Greatrex BW, Bruhl JJ (2020) GC-MS 'chemophenetics' on Australian pinkflowered Phebalium (Rutaceae) using herbarium leaf material demonstrates phenetic agreement with putative new species. Phytochem Lett 38:112-120. https://doi.org/10.1016/j.phytol. 2020.05.014

84. Salem MA, Perez de Souza L, Serag A, Fernie AR, Farag MA, Ezzat SM, Alseekh S (2020) Metabolomics in the context of plant natural products research: from sample preparation to metabolite analysis. Metabolites 10(1):37. https://doi.org/10. 3390/metabo10010037

85. Salzano A, Manganiello G, Neglia G, Vinale F, De Nicola D, D'Occhio M, Campanile G (2020) Preliminary study on metabolome profiles of buffalo milk and corresponding mozzarella cheese: safeguarding the authenticity and traceability of protected status buffalo dairy products. Molecules 25(2):304. https:// doi.org/10.3390/molecules 25020304

86. Samoggia A, Riedel B (2018) Coffee consumption and purchasing behavior review: insights for further research. Appetite 129:70-81. https://doi.org/10.1016/j.appet.2018.07.002

87. Sampaio B, Edrada-Ebel R, Da Costa F (2016) Effect of the environment on the secondary metabolic profile of Tithonia diversifolia: a model for environmental metabolomics of plants. Sci Rep 6:29265. https://doi.org/10.1038/srep29265

88. Senizza B, Rocchetti G, Ghisoni S, Busconi M, Pascual MDLM, Fernandez JA, Lucini L, Trevisan M (2019) Identification of phenolic markers for saffron authenticity and origin: an untargeted metabolomics approach. Food Res Int 126:108584. https://doi. org/10.1016/j.foodres.2019.108584

89. Sherman E, Coe M, Grose C, Martin D, Greenwood DR (2020) Metabolomics approach to assess the relative contributions of the volatile and non-volatile composition to expert quality ratings of pinot noir wine quality. J Agric Food Chem 68(47):13380 13396. https://doi.org/10.1021/acs.jafc.0c04095

90. Springer AE (2019) Wine authentication: a fingerprinting multiclass strategy to classify red varietals through profound chemometric analysis of volatiles. Eur Food Res Technol 245(1):179190. https://doi.org/10.1007/s00217-018-3151-z

91. Suhaj M, Koreňovská M (2008) Study of some European cheeses geographical traceability by pattern recognition analysis of multielemental data. Eur Food Res Technol 227(5):1419-1427. https://doi.org/10.1007/s00217-008-0861-7

92. Sumner LW, Mendes P, Dixon RA (2003) Plant metabolomics: large-scale phytochemistry in the functional genomics era. Phytochemistry 62(6):817-836. https://doi.org/10.1016/S00319422(02)00708-2

93. Theodoridis G, Pechlivanis A, Thomaidis NS, Spyros A, Georgiou CA, Albanis T et al (2021) FoodOmicsGR_RI: a consortium for comprehensive molecular characterisation of food products. Metab 11(2):74. https://doi.org/10.3390/metabo11020074

94. Thøgersen J, Pedersen S, Paternoga M, Schwendel E, Aschemann-Witzel J (2017) How important is country-of-origin for organic food consumers? A review of the literature and suggestions for future research. Br Food J 119(3):542-557. https://doi. org/10.1108/BFJ-09-2016-0406 
95. Torraco RJ (2005) Writing integrative literature reviews: guidelines and examples. Hum Resour Dev Rev 4(3):356-367. https:// doi.org/10.1177/1534484305278283

96. Van Eck NJ, Waltman L (2016) VOSviewer manual: version 1.6.5. Universiteit Leiden, Leiden

97. Vargas LHG, Neto JCR, de Aquino Ribeiro JA, Ricci-Silva ME, Souza MT, Rodrigues CM, de Oliveira AE, Abdelnur PV (2016) Metabolomics analysis of oil palm (Elaeis guineensis) leaf: evaluation of sample preparation steps using UHPLCMS/MS. Metabolomics 12(10):1-12. https://doi.org/10.1007/ s11306-016-1100-z

98. Vatavali K, Kosma I, Louppis A, Gatzias I, Badeka AV, Kontominas MG (2020) Characterisation and differentiation of geographical origin of Graviera cheeses produced in Greece based on physico-chemical, chromatographic and spectroscopic analyses, in combination with chemometrics. Int Dairy J 110:104799. https://doi.org/10.1016/j.idairyj.2020.104799

99. Violino S, Antonucci F, Pallottino F, Cecchini C, Figorilli S, Costa C (2019) Food traceability: a term map analysis basic review. Eur Food Res Technol 245:2089-2099. https://doi.org/ 10.1007/s00217-019-03321-0

100. Wang QQ, Huang HY, Wang YZ (2019) Geographical authentication of Macrohyporia cocos by a data fusion method combining ultra-fast liquid chromatography and fourier transform infrared spectroscopy. Molecules 24(7):1320. https://doi.org/10. 3390/molecules24071320

101. World Trade (2008) Organization. TRIPS: GEOGRAPHICAL INDICATIONS. https://www.wto.org/english/tratop_e/trips_e/ gi_background_e.htm\#general. Accessed 12 Feb 2021

102. Wu H, Tian L, Chen B, Jin B, Tian B, Xie L, Rogers KM, Lin G (2019) Verification of imported red wine origin into China using multi isotope and elemental analyses. Food Chem 301:125137. https://doi.org/10.1016/j.foodchem.2019.125137

103. Xu L, Cai CB, She YB, Chen LJ (2015) Discriminating the geographical origins of Chinese white lotus seeds by near-infrared spectroscopy and chemometrics. J Spectrosc 2015:831246. https://doi.org/10.1155/2015/831246

104. Zheng Y, Ruan G, Li B, Xiong C, Chen S, Luo M, Li Y, Du F (2014) Multicomposition analysis and pattern recognition of Chinese geographical indication product: vinegar. Eur Food Res Technol 238(2):337-344. https://doi.org/10.1007/ s00217-013-2135-2

Publisher's Note Springer Nature remains neutral with regard to jurisdictional claims in published maps and institutional affiliations. 